\title{
A pesca artesanal no baixo rio Araguaia em Araguatins, Tocantins, Brasil
}

\author{
La pesca artesanal en el bajo rio Araguaia en Araguatins, Tocantins, Brasil \\ Artisanal fishing in the low river Araguaia in Araguatins, Tocantins, Brazil
}

\author{
Eliseu Pereira de Brito ${ }^{1}$ \\ Universidade Federal do Tocantins (UFT), Brasil \\ Matheus Miranda Shimasaki ${ }^{2}$
Universidade Federal do Tocantins (UFT), Brasil
}

http://dx.doi.org/10.15359/rgac.67-2.xx

\begin{abstract}
Resumo
Buscamos nesta pesquisa retratar a pesca artesanal no baixo rio Araguaia delimitando uma escala espacial do município de Araguatins no norte do Estado do Tocantins, na Amazônia Legal. Trata-se de um ambiente de floresta amazônica e cerrado nas áreas de transição pertencentes à bacia hidrográfica Araguaia-Tocantins. Para fazer a pesquisa utilizamos do método de pesquisa exploratória qualitativa com pesquisa de campo. Os resultados apontaram que a modernização do território foi demandada pela introdução técnica-científica na pescaria e no território. Modernizou os objetos da pesca artesanal e, ao mesmo tempo, modificou a forma dos ribeirinhos pescadores lidarem com o rio, introduzindo novos conteúdos na concepção de produção e preservação do ambiente.
\end{abstract}

Palavras-chave: Pesca Artesanal, Modernização, Ribeirinhos, Rio Araguaia, Amazônia Legal.

\begin{abstract}
In this research we seek to portray artisanal fishing in the lower Araguaia River, delimiting a spatial scale of the municipality of Araguatins in the north of the State of Tocantins, in the Legal Amazon. It is an Amazonian and cerrado forest environment in the transition areas belonging to the Araguaia-Tocantins hydrographic basin. To do the research we use the qualitative exploratory research method with field research. The results showed that the modernization of the territory was demanded by the technical-scientific introduction in the fishery and in the territory. It modernized the objects of artisanal fishing and, at the same time, modified the way the riverside fishermen deal with the river, introducing new contents in the conception of production and preservation of the environment.
\end{abstract}

Keywords: Artisanal Fishing, Modernization, Riverside, Araguaia River, Legal Amazon.

\footnotetext{
${ }^{1}$ Doutor em Geografia. Professor do Curso de Geografia da Universidade Federal do Tocantins, pesquisador do Grupo de Estudos da Amazônia e Tocantins - GEGATO, desenvolve pesquisa sobre territórios ribeirinhos e territórios tradicionais. E-mail: eliseubrito@uft.edu.br.

${ }^{2}$ Bolsista de Iniciação Cientifica - UFT. Curso de Geografia da Universidade Federal do Tocantins, pesquisador do Grupo de Estudos da Amazônia e Tocantins, desenvolve pesquisa sobre territórios ribeirinhos. Email: miranda.shimasaki@mail.uft.edu.br.
}

Fecha de recepción: 24 de junio del 2020

Fecha de aceptación: 27 de agosto del 2020 


\section{Resumen}

En este estudio, buscamos retratar la pesca artesanal en el bajo río Araguaia, delimitando una escala espacial del municipio de Araguatins, en el norte del Estado de Tocantins, en la Amazonia Legal. Se trata de un ambiente de selva amazónica y cerrado en las áreas de transición pertenecientes a la cuenca hidrográfica AraguaiaTocantins. Para realizar el estudio, utilizamos el método de investigación exploratoria cualitativa con estudio de campo. Los resultados señalaron que la modernización del territorio fue demandada por la introducción técnica-científica en la pesca y en el territorio. Modernizó los objetos de la pesca artesanal y, al mismo tiempo, modificó la forma en que los pescadores ribereños lidian con el río, introduciendo nuevos contenidos en la concepción de producción y preservación del ambiente.

Palabras clave: Pesca artesanal, Modernización, Ribereños, Río Araguaia, Amazonia Legal.

\section{Introdução}

A pesquisa foi desenvolvida no município de Araguatins, na região do Bico do Papagaio, no norte do Estado do Tocantins, Amazônia Legal, Brasil (mapa 01). A formação do município iniciou em 1868; segundo Azevedo (1987, p. 202), “tem 100 casas, muitas d'ellas cobertas de telhas e uma capella muito bonita. [...] Pela lei provincial n. 691 de 9 de Setembro de 1872 foi creado ahi um districto de paz". O município foi criado no ano de 1913 e batizado inicialmente como município de São Vicente do Araguaya, desmembrado do município de Boa Vista (Azevedo, 1987). Por força do Decreto Estadual n. 8.305, de 31 de dezembro de 1943 passou a se chamar Araguatins e em 1948 a sede do município, que estava nas margens do rio Tocantins, em Itaguatins, foi transferida para as margens do rio Araguaia, onde atualmente é o sitio da cidade de Araguatins (Tocantins, 1990).

Importante porto da navegação comercial do rio Araguaia, teve seu crescimento ligado ao transporte de mercadorias e passageiros e a dinâmica produzida pelos ciclos do extrativismo do látex, da castanha-do-pará e da mineração de cristal e diamante. Sua população, na origem, tinha importante quantitativo de migrantes do Nordeste que se direcionaram para o norte de Goiás na formação da frente pioneira de ocupação que avançava para além das áreas de babaçuais sobre a floresta Amazônica.

As terras do município estão inseridas na área transição do bioma Cerrado e Floresta Amazônica, numa confluência entre biomas, formando um fator biogeográfico de distribuição de espécies animais e vegetais e promovendo o encontro natural entre espécies que possuem esses biomas como habitat (A’Sáber, 2003). 
Mapa 1. O município de Araguatins e sua rede de drenagem

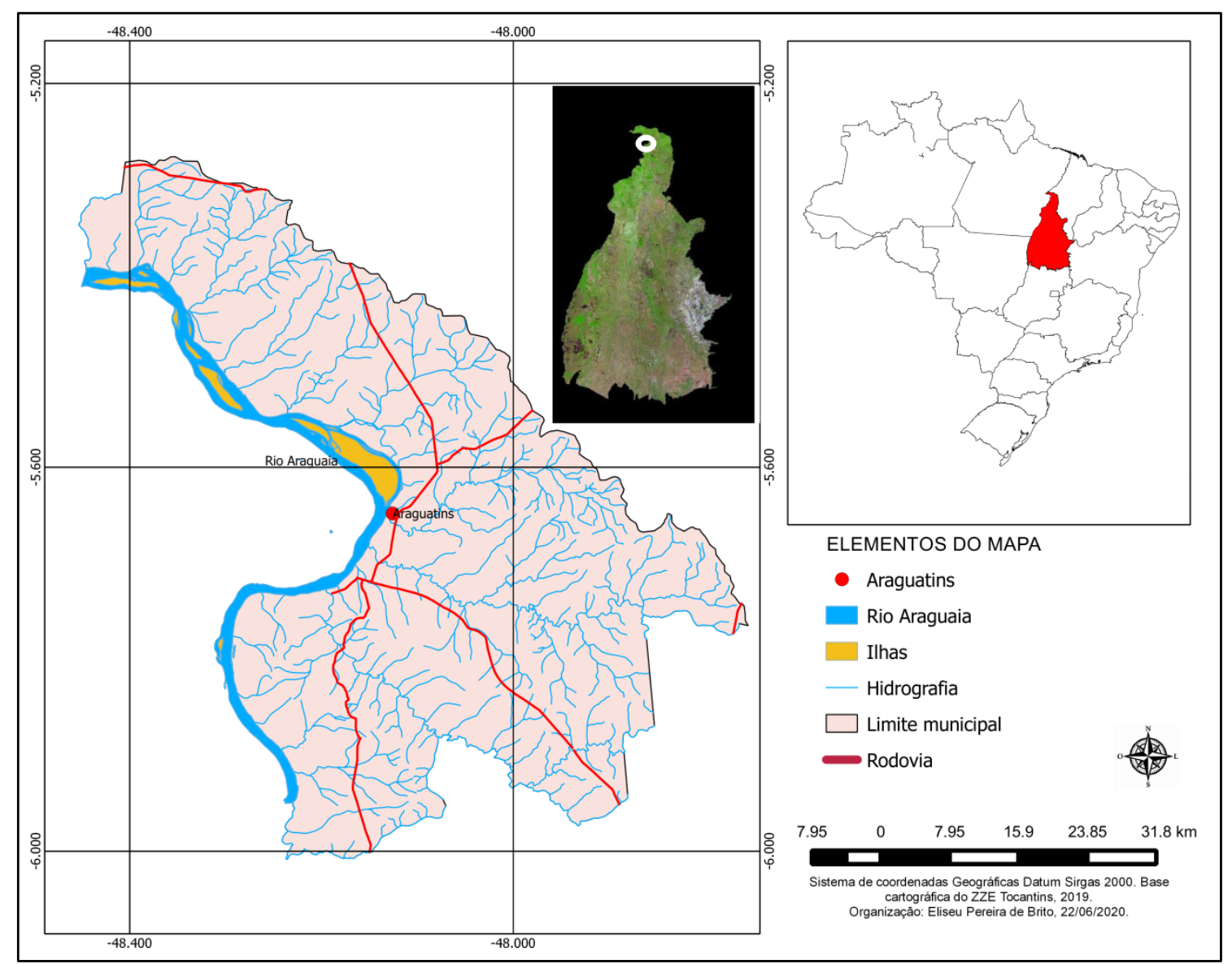

Organizador: os autores, jun. 2020.

Para possibilitar a leitura do espaço pesquisado, objetivou-se no estudo a compreensão do território ribeirinhos e pesqueiras do baixo Araguaia e seus modos de vida e trabalho. Para Lira e Chaves (2016, p. 73),

As comunidades ribeirinhas apresentam, ainda, um modo particular de vida em vários aspectos, tais como: uso do território, uso e manejo coletivo dos recursos locais, orientados por seus saberes e em bases comunicativas e cooperativas; no estabelecimento das relações sociais de trabalho, bem como nas relações de compadrio e parentesco.

Há uma gama de formas e práticas ribeirinhas que podem ser identificadas, como as tradições no uso do território e nas evoluções/revoluções históricos que possibilitaram o surgimento das navegações e dos modos de pescas. Há também importância na compreensão 
de fatores ligados à distribuição das espécies de peixes e seus cardumes pelas regiões hidrográficas do baixo Araguaia, promovendo a análise ligadas à distribuição da ictiofauna e na comercialização do peixe nos mercados peixeiros.

A pesquisa foi possibilitada através de revisões bibliográficas da literatura e pela pesquisa descritiva em campo. O método qualitativo foi construído com fontes primárias, como entrevista e fotografias, além de observações e descrições de paisagem possibilitadas em campo. As fontes secundárias e a organização do texto foram trilhadas de acordo com as leituras e o levantamento bibliográfico sobre a temática ribeirinha e o uso do território ribeirinho no baixo Araguaia.

\section{Embarcações no Araguaia}

A navegação foi o modelo de transportes que pendurou até meados do século $\mathrm{XX}$, nesta borda da Amazônia Legal e o rio Araguaia, a única rota possível de mobilidade regional no sudeste da Amazônia Oriental (Brito, 2009). Os barcos tornaram-se ferramentas necessárias de transportes e sobrevivências, impulsionando a produção de canoas em Araguatins.

De acordo com Silva e Farias (2017), em torno de 19 espécies de árvores eram utilizadas para a construção de embarcações de madeira, dentre as três mais usadas para fazer as tábuas estão o landi (Calophyllum brasiliense Cambess), castanheira (Bertholletia excelsa) e o tamboril (Enterolobium maximum Ducke); e havia outras muito utilizadas como o pequizeiro (Caryocar brasiliense), devido à resistência ao cupim. Mas, até meados do século XX, com a derrubada da floresta para extração de madeira nobre como o mogno (Swietenia macrophylla) houve a construção de lanchas nobres com a espécie. Ter um barco de mogno era objeto de luxo devido o fino acabamento:

A coloração vai desde o marrom avermelhado e marrom amarelado até ao vermelho escuro. O brilho natural confere à madeira beleza muito especial. É preferido para fabricação de canoas e embarcações [...]. Constitui uma das melhores e mais valiosas madeiras de todo o mundo, sendo por isso aplicada em decorações de interiores de requinte, para a marcenaria de arte e de mobiliário (Batista, 2005, p. 14). 
O uso do mogno na cidade também é encontrado em construções como no hotel que se encontra na orla de Araguatins, todo construído com esta madeira. Ter uma embarcação de mogno representava poder aquisitivo alto, dado o preço que o mercado oferecia para aquisição desta madeira. Ainda no presente é possível ver algumas tábuas e vigas de mogno de embarcação nos estaleiros.

Os estaleiros tornaram-se os grandes produtores de barcos que supriram a necessidade de produção de embarcações regionais e ligeiramente contribuíram para o aumento do fluxo de embarcação no rio Araguaia e seus afluentes. A maioria dos estaleiros se localizavam à margem esquerda do porto araguatinense, em uma área de confluência entre os rios Taquari e Araguaia (figura 1). O rio Taquari, por sua vez, também possui características aptas para a navegação de pequeno porte e serviu, por longo tempo, como caminho ribeirinho e de exportação da madeira.

Figura 1. Estaleiros situados na confluência dos rios Taquari e Araguaia.

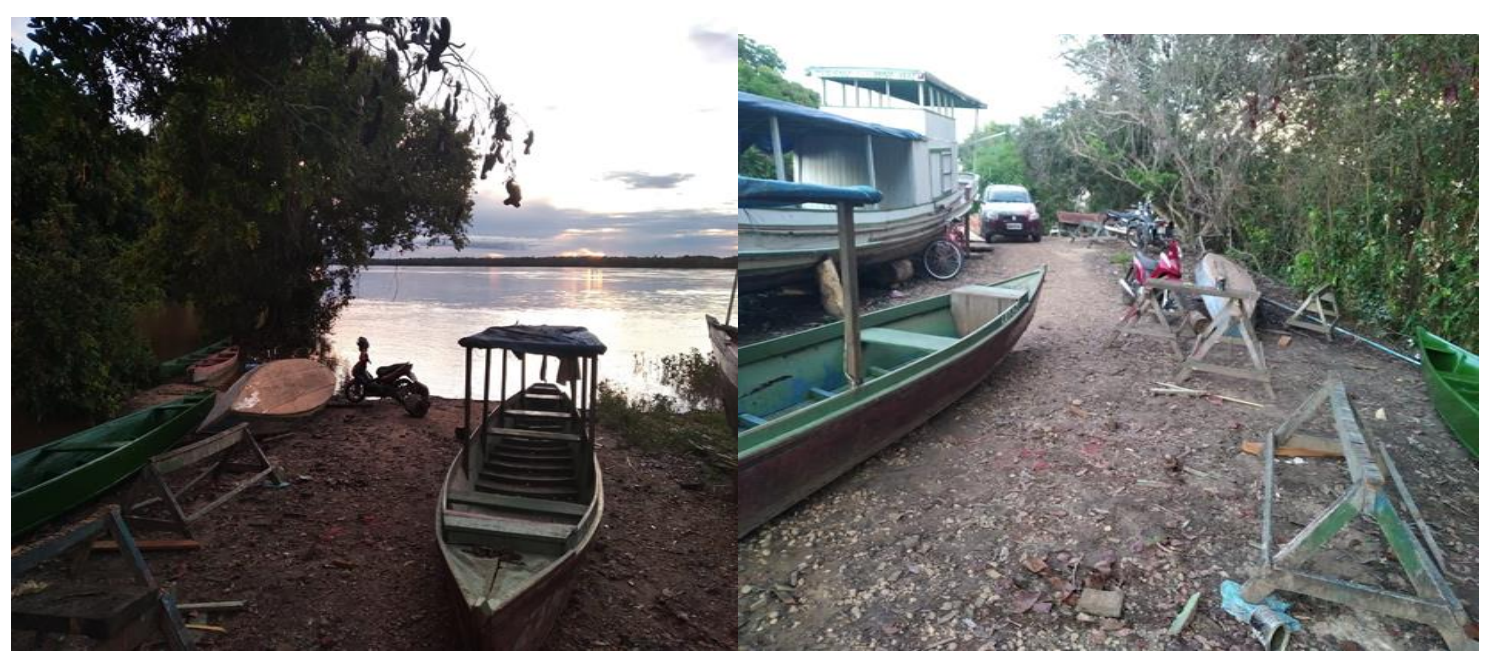

Foto: Os autores, fev. 2020.

De acordo com Silva e Farias (2017), há no rio Araguaia 2.027 barcos em circulação. Destes,

Os materiais básicos para a construção de embarcações para a região do Araguaia foram de quatro tipos, a saber: madeira, alumínio, aço e fibra de vidro. Consoante às embarcações de madeira estas podem ser confeccionadas 
a partir de tábuas de madeira ou construídas a partir de um único bloco/tronco de madeira (localmente chamadas de 'côcho'). (Silva \& Farias, 2017, p. 84)

Ainda conforme os autores supracitados, do quantitativo da frota ativa no rio Araguaia, o município que mais possui barcos é Araguatins, contabilizado em 500 barcos que transportam entre 1 a 5 pescadores por operação de captura dos peixes no rio Araguaia. Conforme levantamento de dados em campo, a maioria dos barcos são de madeira e servem para o transporte dos ribeirinhos, para o trabalho na pesca e atende ao fluxo de turistas no período de temporada de praia de águas doces que acontece nos meses de junho e julho.

\section{A pesca no rio Araguaia}

A pesca no rio Araguaia sempre foi artesanal, realizada em embarcações, movidas pelo remo, ou das margens do rio Araguaia. Os barcos motorizados movidos a diesel ou a gasolina eram extremamente raros para os pescadores de profissão até os anos 2000. O território pesqueiro, dessa maneira, era restrito às regiões próximas ao porto araguatinense, produzindo pescarias rápidas e objetivas. Ao se direcionar ao rio, o pescador possuía, de certa forma, um cronograma, tendo em foco uma espécie ou cardume, e uma meta de quilogramas de pescado necessários para suprir suas necessidades e vendas, a fim de não acarretar desperdícios do pescado. Para cumprir com suas metas de entrega do pescado, utilizava de armadilhas, redes, iscas e suprimentos, e técnicas e saberes da pesca, todos bem calculados, para garantir o sucesso da pescaria.

Para atender o mercado de venda do pescado eles focam em espécies de maior procura comercial, como exemplo os peixes de couro e peixes considerados de carne e sabor nobre.

Silva, Ummus e Tardivo (2017) identificaram 11 espécies de peixes mais capturados no rio Araguaia que totalizam 25\% das espécies e $80 \%$ do volume de pescados (Figura 2). Estas espécies possuem nomes diferentes, ditos como populares como o pacu, denominado na região de acordo com sua morfologia e apelidada de pacu manteiga, pacu dente seco, pacu São Pedro, pacu vermelha, pacu lombo de folha e pacu preto.

Cada espécie de pacu, de acordo com os pescadores, tem seu valor e isso é decorrente ao sabor do peixe. Os três peixes mais pescados no rio Araguaia são “(pacu, curimatá e piau) 
são de base de cadeia trófica e de hábito forrageiro, pertencentes à ordem Characiformes" (Silva, Ummus \& Tardivo, 2017, p. 18).

Figura 2. Produção de peixes por espécies e por municípios ao longo do rio Araguaia no Estado do Tocantins.

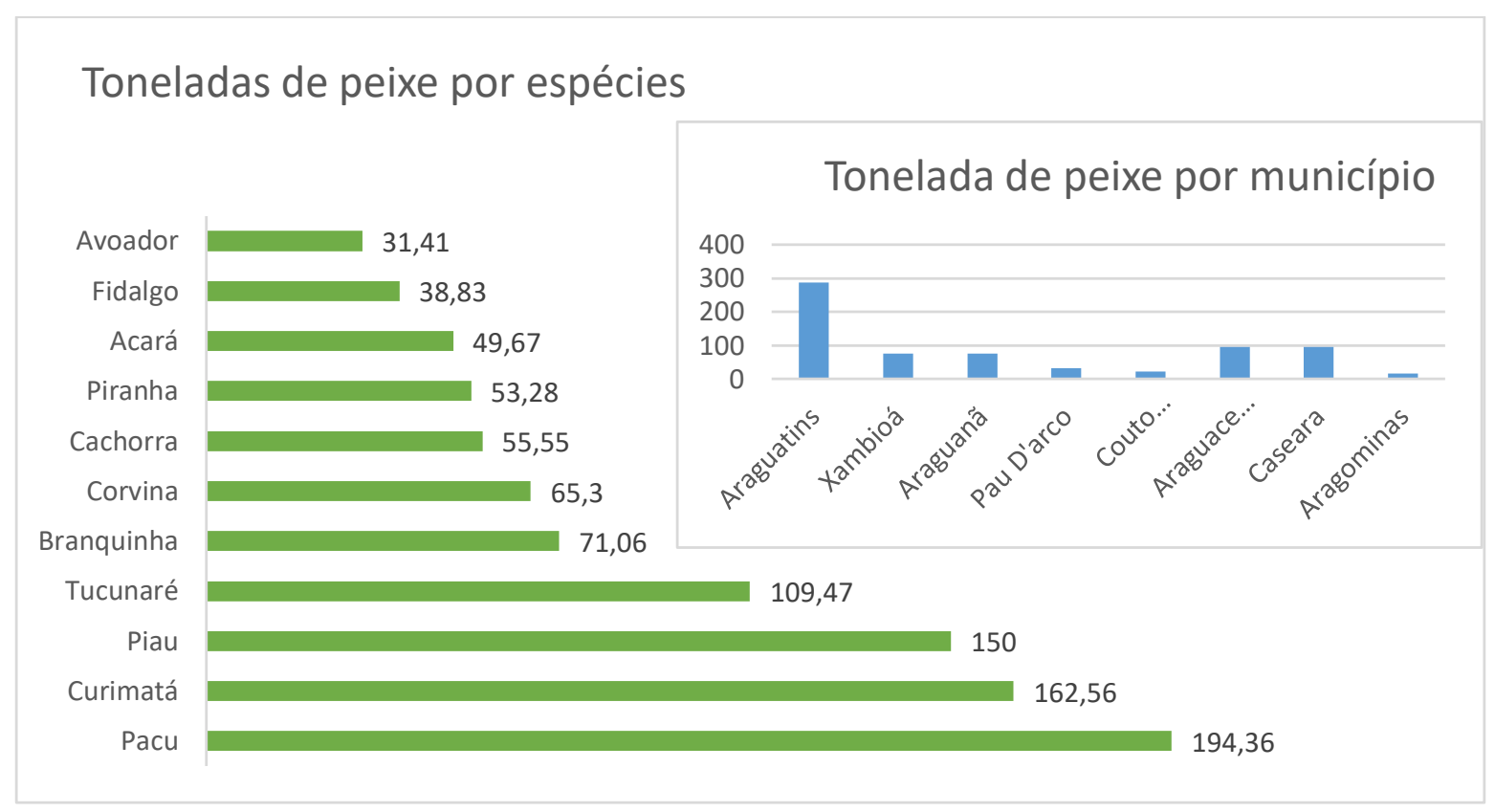

Fonte: Brasil, 2006; Silva \&Farias, 2017. Os dados por município constam no Censo Estrutural da Pesca e as informações por pescado em dados produzidos pela EMBRAPA.

Em Araguatins a produção média de pescado por mês no município é de 500kg de peixe sendo $0,6 \mathrm{~kg}$ por pescador. O município possui a maior extensão de terras banhada pelo rio Araguaia do norte do Estado do Tocantins, totalizando $98 \mathrm{~km}$ de área pesqueira e contabiliza mais de 1.100 pescadores cadastrados. Vale ressaltar que nem todos pescadores cadastrados tem a pesca como ofício de trabalho o que identificamos três grupos de pescadores: os pescadores artesanais que sobrevivem da pesca; os pescadores amadores que pescam por esporte; e os pescadores que exercem outras atividades e que pescam ocasionalmente. 
Figura 3. Espécies de peixes e formas de capturas do pescado no rio Araguaia

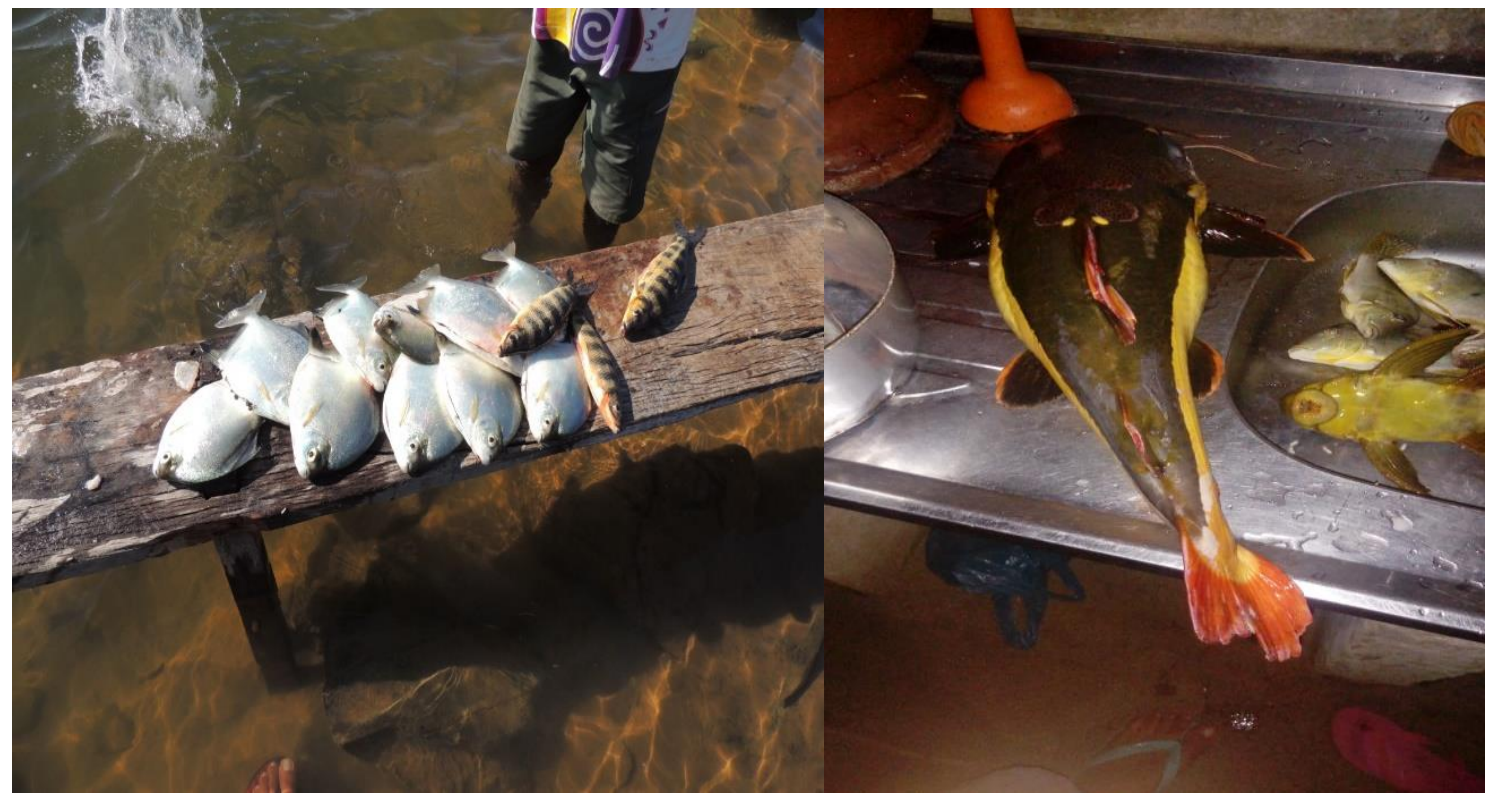

Fotos: Os autores, agosto de 2019. Os pescadores do rio Araguaia se aperfeiçoaram na captura de determinadas espécies de peixe. Na primeira imagem um pescador que utiliza cevas e captura duas espécies: a Pacu Manteiga e o Piau Flamengo. Na segundo foto, a pescaria é feita de forma aleatória e por rede. Três espécies de peixe são identificadas: o Pirara, peixe de couro muito temido devido a sua braveza nas águas, o Cari e o Cará. Estas espécies não são cevadas e os pescadores utilizam seu conhecimento do rio para a captura das mesmas.

O país foi dividido em 04 regiões de pesca: Continental Amazônica, Continental Nordeste Centro-Sul, Marinha Norte-Nordeste e Marinha Sudeste-Sul (Brasil, 2020). A bacia do Araguaia-Tocantins faz parte da região Continental Amazônica, a principal bacia de pescado de águas doces do Brasil. O rio Tocantins desagua no rio Pará e este se conecta ao rio Amazonas por meio do furo de Breves (A’Sáber, 2003).

Devido a não correnteza das águas de um furo, não há tributação entre os dois rios; para tanto, as duas bacias são independentes, mas a ictiofauna circula de um rio para outro. As interrupções da mobilidade da ictiofauna acontecem devido às obras inacabadas de construção de eclusas do rio Tocantins, reclamada pelos pescadores que notaram uma redução das espécies e da quantidade de peixes no rio Araguaia ainda em meados da década de 1980 com a construção da UHE Tucuruí, conforme relatos de campo com os ribeirinhos.

Os métodos mais utilizados para a obtenção dos pescados são o uso de anzol e redes. De acordo com Dias e Silva (2017, p. 1154), as redes de emalhe tecida em poliamida são as mais utilizadas nas pescarias na forma de espera, caceia e tarrafas. 
$\mathrm{Na}$ 'espera' o petrecho fica estacionado em locais estratégicos a espera da espécie-alvo, enquanto na 'caceia' a rede fica à deriva na correnteza junto com o barco e vai de encontro dos cardumes previamente identificados. As ‘tarrafas' são mais utilizadas em áreas mais rasas, próximo às margens.

Há fatores como a dinâmica das correntezas dos rios e as fases da lua que determinam o uso das redes pelos pescadores. Trata-se de conhecimentos e saberes adquiridos por gerações de famílias de pescadores sobre o rio Araguaia.

Para Brito (2018), os ambientes de pesca determinam uma rede de lugares e itinerários no rio Araguaia, fator de construção de territórios. Para Ummus, Silva e Paz (2018, p. s.n), foram identificados 18 ambientes conhecidos pelos pescadores, "remanso, canal do rio/purão/correnteza, pedral, gorgulho, margem, beiradão, pé de moita/galhada, lago e ilha, ressaca, camboa/furo, travessão/cachoeira/corredeira e praia, varjão, vareda, rebojo, razio, mata e barranco".

Estes ambientes ou apenas as cevas, lugares em que coloca o alimento para os peixes, são lugares estudados cautelosamente pelo pescador e há um consenso social entre eles para não invadir as cevas de outros.

Os pescadores buscam conhecer o fluxo de cardumes que percorrem o território, estudando desde os hábitos alimentares da espécie, como frutos que caem de determinada vegetação, por exemplo a azedinha, também chamada na região de camucamu ou araçád'água (Myrciaria dubia; Myrtaceae), ou até mesmo o volume e temperatura da água daquele determinado local, sabendo eles que existem padrões de aceitação das espécies pelas condições da água, corrente ou de rebojo calmo, temperaturas mais frias ou mais quentes. Até mesmo as fases da lua e a superstições ribeirinhas, segundo os pescadores do baixo Araguaia, determinam o sucesso ou insucesso da pescaria.

Este fator remete a um cenário de alta predação de espécies, o que contribuiu para o desequilíbrio do fluxo natural dos cardumes, agravados pelo desequilíbrio ambiental gerado pelo intenso processo agrícola, urbano e minerador sediado às margens do rio Araguaia, possibilitando o desaparecimento de cardumes dos territórios próximos ao porto de Araguatins.

Desta maneira, a distribuição das espécies e cardumes sofrem suas primeiras alterações graças à presença do homem em seu espaço e habitat. A contaminação do rio 
Araguaia e de seus afluentes através de aditivos agrícolas, como agrotóxicos e fertilizantes, a contaminação dos solos através de manejos inapropriados, o despejo do esgoto doméstico e industrial diretamente nos cursos d'água no rio Araguaia (Moss \& Moss, 2007, p. 74), todos esses fatores geram impactos ambientais, contribuindo para o desequilíbrio e a expulsão de determinadas espécies das proximidades urbanas.

O condicionamento que ainda possibilitava o equilíbrio entre a pesca e o pescado, estava relacionado ao arsenal limitado do pescador, que possuía apenas a canoa a remo, as redes. O sal e o sol para a secagem do peixe eram os únicos elementos utilizados para a conservação do pescado.

Os mercados, a oportunidade mais legítima de vendas, eram realizados aos domingos na feira municipal. O pescador se tornava também um comerciante buscando a venda de seu pescado. Semanalmente o peixe também poderia ser vendido logo ao aportar de suas canoas no porto, ou vendidos de porta em porta, pelas ruas da cidade, entrelaçados em uma espécie de trançada de cipós.

\section{A modernização da pesca no baixo Araguaia, motores de popa e o surgimento} da geleira municipal

Para Castilho (2014), as modernizações territoriais são processo de expansão do capitalismo nos lugares. $\mathrm{O}$ autor fundamenta sua análise pelo processo de produção e no debate que estradas e eletricidade são elementos de uma modernização pois alteram as dinâmicas territoriais. Afirmamos que, para além da modernização vista em objeto, ela está na forma como os sujeitos passam a lidar com os processos e os utilizam no território.

Ao fazermos um contraponto com a pesca, em Araguatins houve uma modernização territorial ou mesmo uma dinâmica no tempo de uso e de permanência no rio devido a fatores tecnológicos como o barco motorizado e a disponibilidade de gelo; ao mesmo tempo, novos conteúdos técnicos e científicos incorporados em traias de pesca e mercados de venda do pescado. As contribuições ditas até mesmo "revolucionárias" para a pesca, e para o pescador araguatinense, estão relacionadas ao surgimento de motores de popa, movidos por combustíveis acessíveis e baratos como o óleo diesel e a gasolina. Para Silva e Farias (2017, p. 86), 
As embarcações do rio Araguaia utilizam propulsão manual com o auxílio de remo e "zinga", sendo esta última constituída por uma vara de madeira com boa resistência e tamanho suficiente para navegar nas margens do rio, deslocando a embarcação quando o pescador empurra a zinga em contato com o leito do rio. Adicionalmente, constatou-se também as embarcações munidas com propulsão mecânica (motor de "rabeta" e popa), sendo a maioria detentora de motores tipo rabetas. A escolha por embarcações com motor de rabeta deve-se ao seu menor custo de aquisição e manutenção. A potência encontrada nos motores de rabeta utilizados nas embarcações de tábuas variou de 5 a 9 HP. Já as embarcações de alumínio podem utilizar tanto os motores de rabeta (3 a $15 \mathrm{HP}$ ) quanto de popa (15 a $25 \mathrm{HP}$ ), sendo estes últimos predominantes. (Silva \& Farias, 2017. p. 86).

Há de se frisar que a modernização não é homogeneizadora; antes produz desigualdades vistas nas próprias embarcações, em que as movidas pelo remo convivem com barcos motorizados e lanchas na navegação no rio Araguaia. Não que esta desigualdade seja algo do tempo presente, pois os barcos de mogno já ditavam o poder aquisitivo entre os barqueiros há décadas.

Outro fator ponderador no processo trata-se dos saberes de navegação pelo rio. Há barqueiros que se direcionam para a cachoeira de Santa Isabel, a maior do rio Araguaia, com barco pequeno de madeira, outros, mesmo com motores potentes não conseguem passar pelos $10 \mathrm{~km}$ das corredeiras e cachoeiras lapidadas em rochas metamórficas.

Os motores industriais possuem, entre suas vantagens, a adaptação e instalação em canoas e rabetas produzidas em estaleiros locais, possibilitando aos pescadores uma extensão maior no rio com ampliação do território de pesca e o encurtamento do tempo de suas viagens. Isso não substitui a forma de vida do ribeirinho pescador, que ainda tem o costume de acampar dias ou semana nas margens do rio em pescaria em grupo ou individual (figura 4). 
Figura 4. Acampamento de pescadores ribeirinhos nas margens do rio Araguaia.

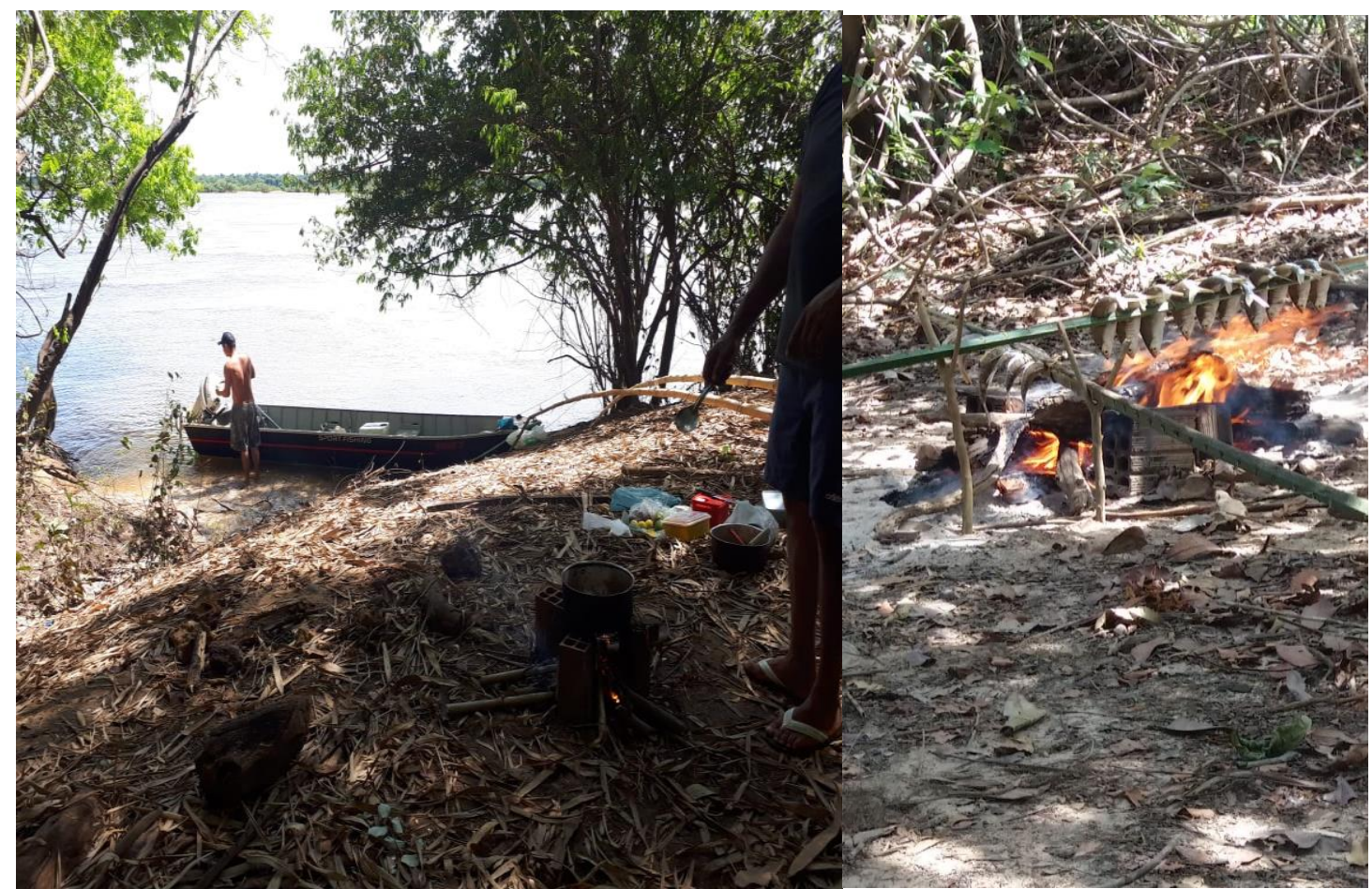

Foto: Os autores, jun. 2020. No período das estiagens que vai de maio a outubro, os pescadores montam acampamentos as margens do rio Araguaia e costumam passar de terça-feira a sexta-feira acampado pescando.

Os acampamentos foram elementos que, na pesquisa, identificamos como de permanência dos territórios. Mesmo com o barco a motor produzindo novas mobilidades e alterando o tempo de permanência no rio Araguaia, o pescador ainda preserva a tradições de acampar. As cevas constituem lugares de posse no rio vigiada pelo pescador que a mantem próxima ao seu acampamento. Mas, conforme o peixe a ser coletado, o pescador construiu itinerários pelo rio, pelos saberes de gerações das águas frias, quentes e do deslocar dos cardumes pelo rio. Estas redes de lugares e itinerários é que denominamos de territórios ribeirinhos, fundamentados na teoria de Bonnemaison (1987). Para o autor, o território é uma rede de lugares e itinerários interconectados.

Outro elemento merecedor de destaque é a instalação de uma fábrica de gelo, batizada como Geleira Municipal, logisticamente acessível, localizada aproximadamente a 40 metros do Cais do Porto e 250 metros da feira municipal, popularmente conhecida como Feira Coberta. Ela é responsável pela produção e venda de gelo para os pescadores. A partir do momento em que o gelo é comprado e armazenado corretamente pelo pescador, o período de validade da pesca é ampliado. 
O pescador possui um tempo maior para desenvolver suas técnicas e práticas de pesca, pelo fato do gelo ser naturalmente um elemento com propriedades de conservação de alimentos. O processo de modernização da pesca está diretamente ligado à implantação das estações de energia elétrica na região, que possibilitaram, além da fabricação do gelo na Geleira, o sustento dos freezers em domicílios, conservando o pescado por períodos mais longos no conforto de seus lares.

A lógica da comercialização do peixe também foi alterada. Antes muito mais utilizado seco para conservar, hoje muito mais vendido fresco, atendendo o novo perfil de consumidores do pescado. A Geleira que fornece o gelo também é um mercado de compra e venda de pescado (figura 5).

Os mesmos pescadores que anteriormente compraram o gelo, posteriormente tem a opção de comercializarem seu pescado para atravessadores na Geleira. Este fator só é interrompido no período da piracema em que fica vedado o transporte, a comercialização, o beneficiamento e a industrialização de espécimes provenientes da pesca. (Tocantins, 2019). Neste período o peixe é comprado de fazenda de criatórios de peixe do município.

Figura 5. Geleira Municipal organizada pela Colônia de Pescadores.

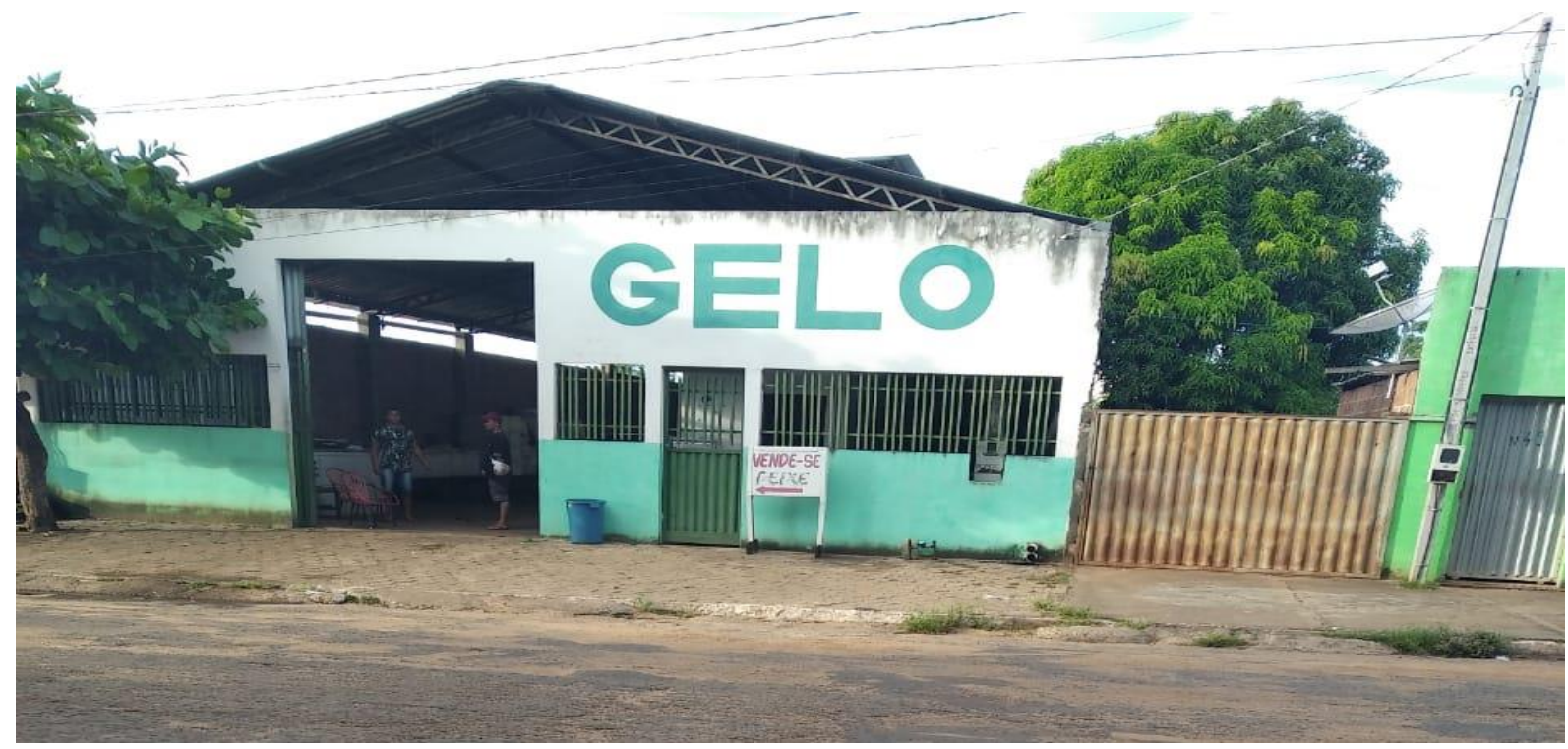

Foto: os autores, dez. 2019. A geleira tem capacidade para produção de uma tonelada de gelo por dia. A produção atende principalmente os pescadores para a conserva do pescado. 
Esta mescla de fatores possibilitaram ao pescador novos nortes com a introdução de novas tecnologias, acompanhadas pelos aprendizados e técnicas repassadas por gerações que construíram um modelo de pesca mais objetiva e com níveis predatórios mais elevados. O moderno possibilitou novos territórios de pesca, novas instalações de armazenamento do pescado, além de possibilitar maiores níveis de escoamento dos produtos do rio, assim como acelerou o crescimento do tráfego fluvial de embarcações, graças à velocidade e precisão de embarcações modernas (figura 6).

Figura 6. Embarcações aportadas às margens do rio Araguaia.

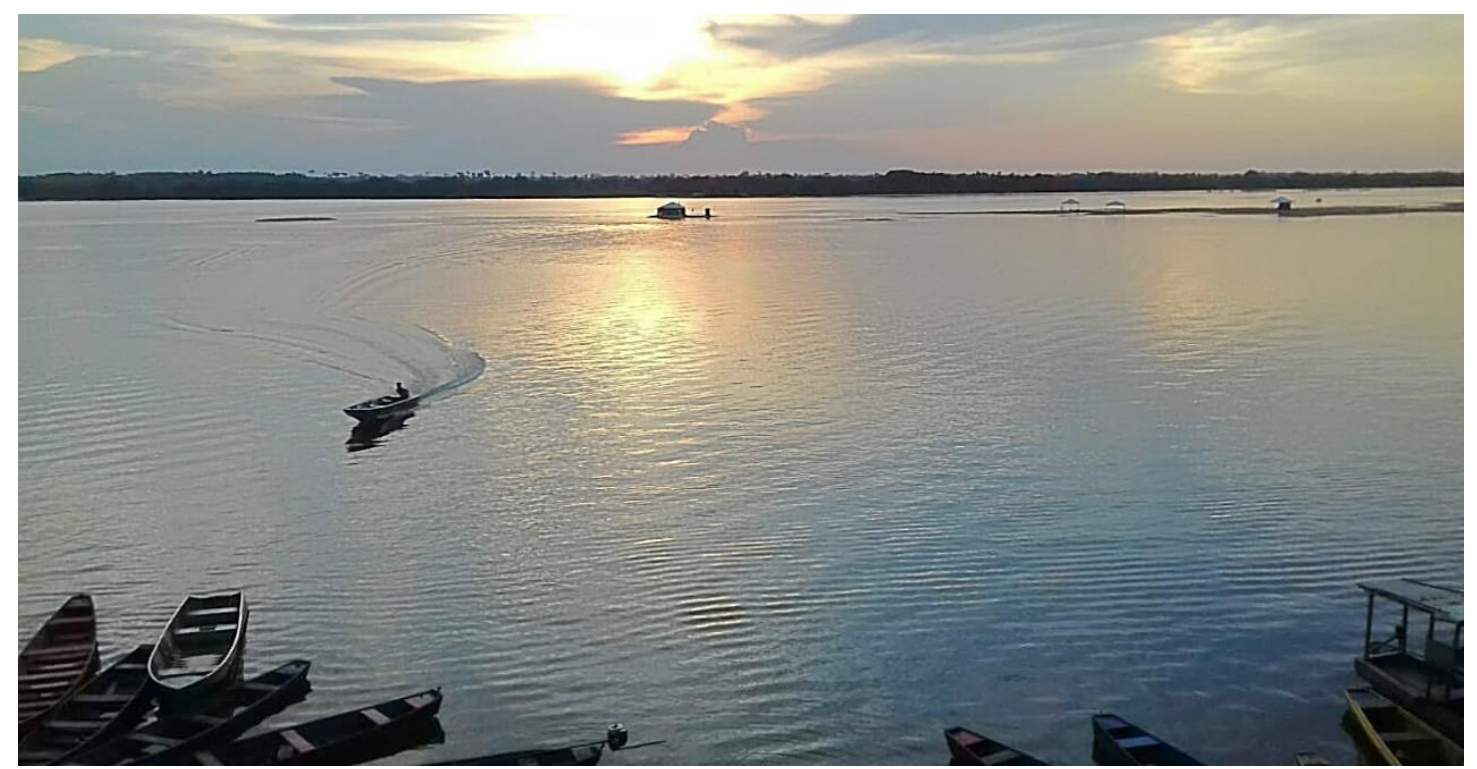

Foto: os autores, jul. 2019.

Desta forma, os números de cardumes foram drasticamente reduzidos; o pescado, antes concentrado em peixes tidos como nobres, foi sucumbido; espécies tidas como de sabor inferior começaram a serem predadas igualmente a espécies de peixes mais valorizados no passado, provocando um novo desequilíbrio geográfico na ictiofauna do rio Araguaia.

Os relatos das comunidades pesqueiras remetem aos caminhos realizados pelos cardumes para fugir da predação humana. Cardumes antes encontrados em um raio de 5 quilômetros do Cais do porto araguatinense, hoje se encontram em águas turbulentas e profundas, até mesmo turvas, áreas de características mais rochosas, como os paredões de rochas e afloramentos rochosos, conhecidos popularmente como cachoeiras. 
Dentre estas localidades é citável: Cachoeira do São Bento, Jacaré Grande, Santa Rosa, Travessão, Rebojo, Nego Velho etc. Espécies não tão adaptáveis a estas condições físicas da água continuam a se propagar em áreas mais distantes, próximas a ilhas, como o caso dos cardumes de pacu e corvina que buscam hoje, entre seus locais, uma ilha, conhecida popularmente como Praia da Melancia, para se refugiarem.

Em uma escala de reprodução das espécies, as pouco ou nulamente predadas pelo homem possuem uma vantagem reprodutiva, provocando, de tal maneira, um ciclo vicioso que possibilita um futuro cenário de desequilíbrio entres espécies.

\section{A organização social dos pescadores araguatinenses e a piracema}

Durante décadas as famílias araguatinenses mantiveram seu sustento em atividades economicamente facilitadas pelo rio Araguaia. Esta sobrevivência remete a uma cadeia ampla de produção, onde o peso econômico do sustento familiar era diversificado pelo rio e suas possibilidades lucrativas ou apenas de subsistência.

A pesca sempre manteve sua importância para a região, porém outras atividades econômicas, como o extrativismo do Mogno e da Castanha do Pará, o transporte e a venda de recursos extrativistas regionais, cupuaçu, açaí, babaçu, bacuri etc., mantiveram a diversificação das atividades familiares.

No que tange às repartições de tarefas por gênero, os homens trabalhavam com a pesca artesanal, no transporte de madeira retirada das matas locais, na retirada de sedimentos como argila das margens do rio para abastecer as olarias e na atividade pecuária. As produções agrícolas de vazantes ou roças de vazantes, em culturas anuais como a mandioca, também eram atividades praticadas pelo homem e, em se tratando desta cultura, a mandioca

é uma das bases da alimentação ribeirinha, tanto na farinha de mandioca como no polvilho e na própria mandioca cozida.

Já as mulheres possuem funções de beneficiamento dos produtos obtidos pelo seu grupo familiar, exercem a função de lavadeiras de roupas no rio, a função de quebradeiras do coco babaçu, descascadoras de mandioca e de dona de lar. Consequentemente, produz desde o sabão ao azeite do coco babaçu, produtos utilizados diariamente no modo de vida ribeirinho (figura 6). 
Figura 6. Produtos artesanais de fabricação feminina no município de Araguatins.

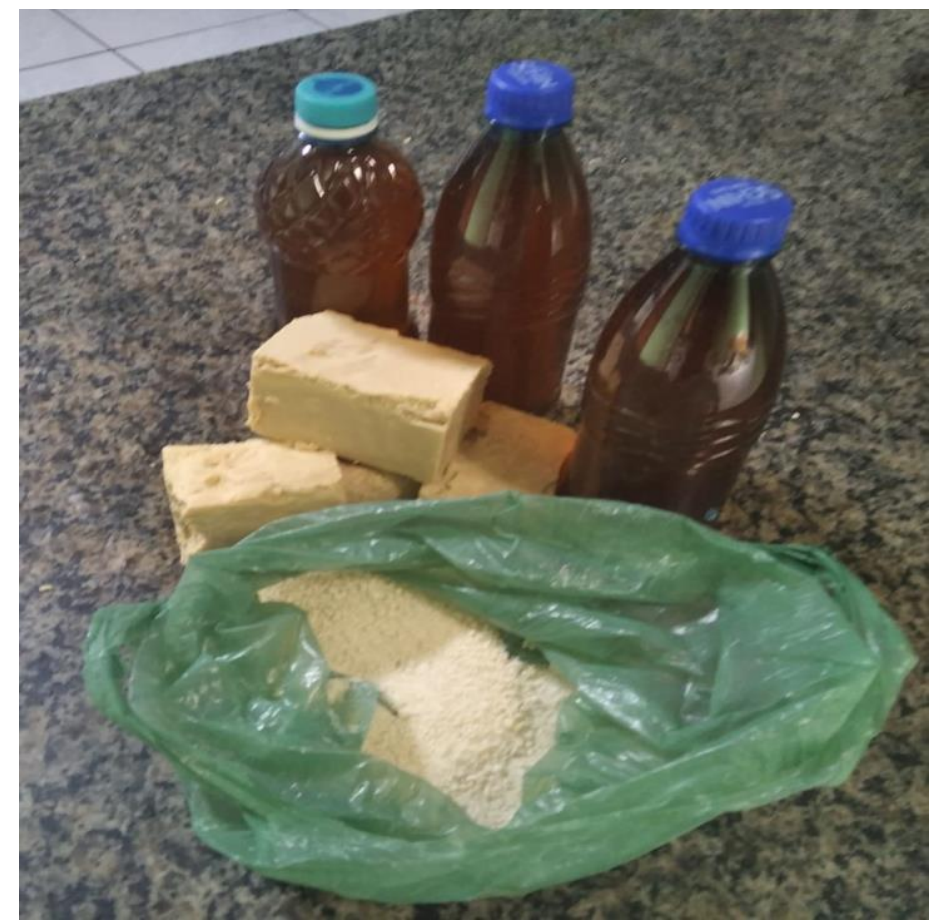

Foto: Os autores, fev. 2020. Na foto temos o azeite do babaçu, sabão de coco do babaçu e farinha de mandioca. Estes produtos em $90 \%$ de seu preparo são fabricados pelas mulheres.

O uso dos derivados do coco babaçu pelas mulheres ribeirinhas é uma tradição regional já descrita pelos navegantes (Gomes, 1862). De acordo com Valverde (1985), a economia do extrativismo do babaçu ditava a dinâmica nos fluxos de mercadorias exportadas. Havia uma organização em cooperativas e associações de quebradeiras de coco que vendiam para o mercado de Belém, sendo uma das rotas da exportação os rios Araguaia e Tocantins.

Então, para além dos usos domésticos em azeite e sabão, houve uma economia de exportação do babaçu na região que funcionou no mesmo sistema de aviamento da borracha e da castanha (Brito \& Silva, 2020). As vendas (uma mercearia) intermediavam a compra do coco e fazia uma negociação por trocas de mercadorias como o açúcar, sal etc. (Brito \& Almeida, 2017).

Segundo Silva e Farias (2017, p. 84), “Tanto o homem quanto a mulher desempenham funções ativas nas pescarias, realizando tanto a captura quanto os afazeres complementares (tratamento do pescado, cozinhar, limpar a embarcação, montar acampamento, etc.)”. 
Os pescadores estão organizados em associação denominada de Z-1 (figura 8). A geleira e a organização social dos pescadores são de responsabilidade legal da Colônia de Pescadores de Araguatins, órgão responsável pelo cadastramento dos pescadores para credenciamento e auxilio emergencial para pescadores (Medida Provisória, nº 908/2019) no período da piracema.

Durante o período da piracema, época de reprodução das espécies que corresponde anualmente aos meses de novembro ao derradeiro dia do mês de fevereiro em todo território tocantinense, a atividade pesqueira é permitida apenas em ocasiões remetentes a subsistência familiar, conforme a legislação do Instituto Natureza do Tocantins, 2019,

Art. $1^{\circ}$ Fixar o período de defeso da Piracema entre $1^{\circ}$ de novembro de 2019 e 29 de fevereiro de 2020 e proibir, neste período, o exercício da pesca em todas as suas modalidades, nos rios, lagos ou qualquer outro curso hídrico existente no Estado do Tocantins, inclusive a promoção de campeonatos ou torneios de pesca, sem prejuízo do disposto na Instrução Normativa - IN n ${ }^{\circ}$ 24, de 04 de julho de 2005, do Ministério do Meio Ambiente - MMA. (Tocantins, 2019, p. s.n).

Foto 8. Colônia de Pescadores de Araguatins - Z1.

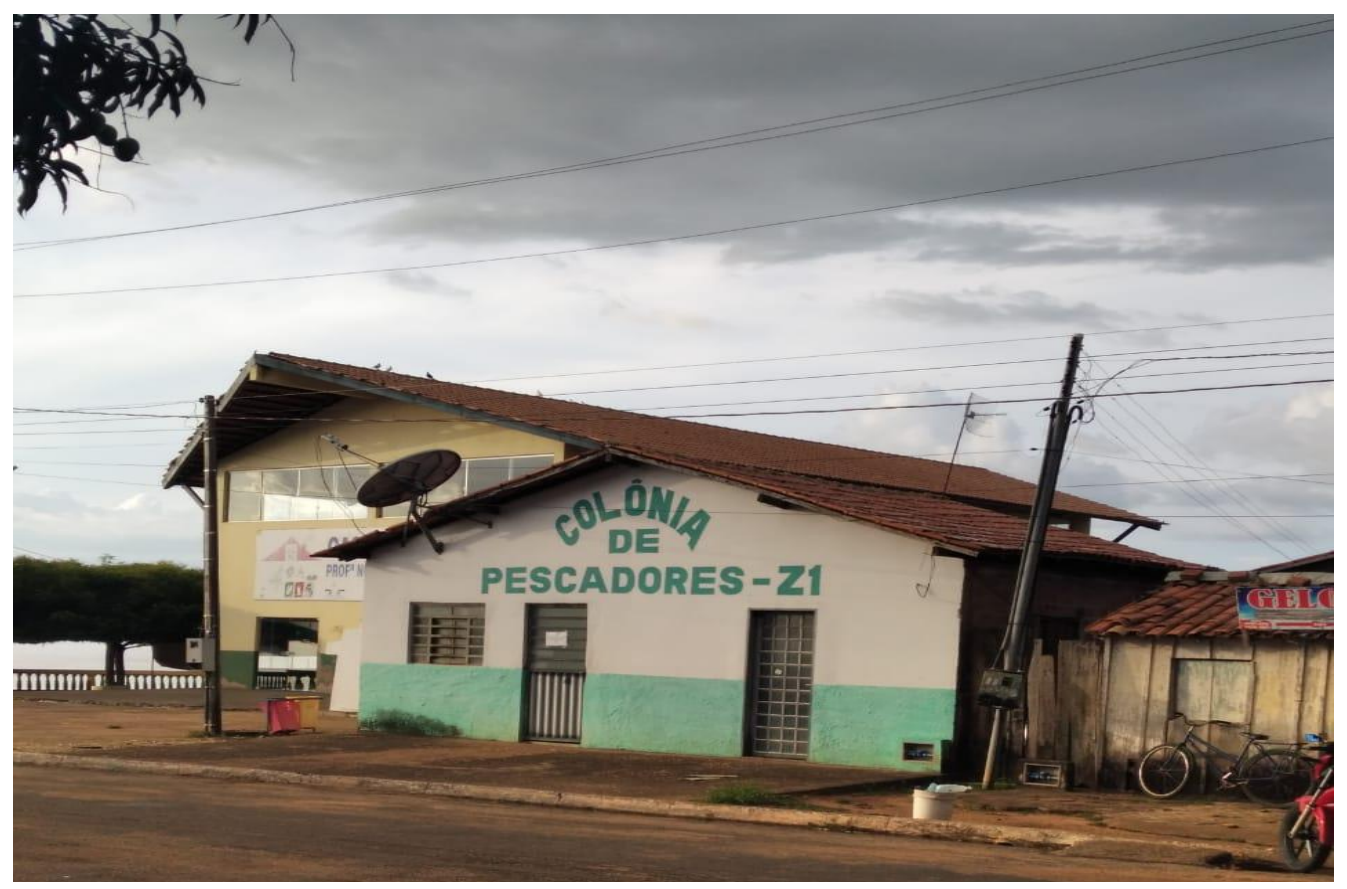


Foto: os autores, mar. 2020. Ao longo do rio Araguaia no Estado do Tocantins, existem mais de 10 colônias de pescadores com sedes nas cidades ou em povoados as margens do rio. No Estado do Tocantins são 37 colônias de pescadores com mais de 7 mil pescadores registrados de acordo com dados do Ministério da Agricultura, Pecuária e Abastecimento.

Produtos retirados do rio neste período em nenhuma hipótese podem ser comercializados, nem pescados com o uso de redes, tarrafas, arpões, zagaias e demais armadilhas como o regionalmente conhecido espinhel. $\mathrm{O}$ espinhel trata de uma armadilha cruel e altamente predatória, sem filtros de espécies e tamanhos, sendo responsável por mortes de animais não comerciais e não consumíveis para alimentação humana, como os botos de diferentes espécies, segundo relatado por pescadores araguatinenses, até mesmo a presença do Boto-Rosa na região do baixo Araguaia, em Araguatins.

Os únicos instrumentos legais disponíveis para a pesca são as linhas de mão, caniços, anzóis, castores, também conhecidos como encastoador, e chumbadas; a união destes instrumentos formam o kit de pesca mais simples e menos predatório possível, inviável para a pesca comercial. Segundo o Instituto Natureza do Tocantins,

II - A pesca de subsistência praticada por ribeirinhos, assim considerada aquela exercida por pescador artesanal ou população ribeirinha com finalidade de consumo doméstico ou escambo sem fins lucrativos, desembarcado ou em barco a remo, utilizando exclusivamente apetrechos do tipo caniço simples, linha de mão e anzol, sendo vedada a comercialização e o transporte do pescado. (Tocantins, 2019, p. s.n).

Atualmente, a pesca do pirarucu é proibida plenamente em todo o Estado do Tocantins. A legislação que assegura medidas preventivas como a piracema e a fiscalização dos instrumentos legalmente permitidos para a pesca serve para rebater os índices desenfreados da atividade pesqueira moderna, combatendo os altos números sintetizados pela predação humana.

No período da piracema muitos pescadores dedicam-se à plantação de lavouras e ou trabalham na construção civil na cidade. As roças fora das margens do rio sempre são praticadas nos fundos dos quintais, uma vez que as terras de vazantes serão/estão inundadas pela cheia de verão do clima tropical no Tocantins. 


\section{Considerações finais}

Os saberes ribeirinhos possibilitam aos sujeitos pescadores uma garantia de sobrevivência do rio. Estes sujeitos se sentem o rio e são eles que mantém uma relação de interdependência. Ao mesmo tempo que dependem do rio Araguaia para sua sobrevivência, este necessita deles para sua preservação. Os pescadores artesanais são homens e mulheres que tem consciência da importância da manutenção das espécies.

A lógica do tempo inserida na modernização do território, que altera também a forma de lidar com rio, tem conteúdo de introdução de novas técnicas, mas também tem conteúdo difundido no sentido da preservação das águas e de sua ictiofauna. Esses conhecimentos surtem efeito a partir do momento em que os pescadores incorporam nos seus saberes e potencializam a pesca com racionalidade. Nem sempre isso se faz de forma harmônica; na maioria dos casos se impõem pelo conflito advindo do próprio processo de modernização gerador de desigualdades.

O principal município produtor de pescado no Tocantins tem a melhor área de produção, espacialmente distribuída entre corredeiras e canais rasos e profundos. Os saberes centenários da pesca no rio Araguaia dão expertise ao pescador para conhecer os lugares e itinerários de pesca. Sobre estes constroem cevas e caminhos dos cardumes, bases de reconhecimento de seus territórios. Podemos afirmar, então, que o rio é demarcado por posses imaginárias, já que trata de um espaço público da Marinha do Brasil. São as redes de lugares

de cevas e pesca e seus itinerários de saberes sobre o rio que reconhecemos como seus territórios.

Estes territórios passam por novos conteúdos de usos e isso se dá pela dinâmica dos tempos de permanência no rio produzido pela disponibilidade de mais rápida locomoção dos barcos motorizados e nas disponibilidades dos gelos para conservação do pescado. Ao mesmo tempo em que altera o tempo cria também desigualdades territoriais pela dinâmica da acessibilidade de todos ao processo de modernização. 


\section{Referencias}

A’Sáber, A. N. (2003). Os domínios de natureza no Brasil: potencialidades paisagísticas. São Paulo, Brasil: Ateliê, p.159.

Azevedo, F. F. S. (1987). Annuario histórico, geográfico e descriptivo do Estado de Goyaz para 1910. Brasília, Brasil: Ministério da Cultura, p.240.

Batista, T. F. C. (2005). Resistência induzida ao mogno brasileiro (Swietenia macrophylla King) por meliáceas resistentes no controle da broca (Hypsipyla grandella Zeller, 1848) em consórcio e em sistema agroflorestal (Doctoral dissertation, UFRA). Disponível em: http://repositorio.ufra.edu.br/jspui/bitstream/123456789/781/1/Resist\%C3\%AAncia $\% 20$ induzida\%20ao\%20mogno\%20brasileiro.pdf. Acesso em: 08 jun. 2020.

Bonnemaison, J. (1987). Les fondements géographiques d'une identité. L'archipel du Vanuatu. Paris, França, pp.199-205.

Brasil, Ministério da Agricultura (2020). Região pesca. Disponível em: https://spark.adobe.com/page/Cza9NBk3AbHni/. Acesso em: 09 jun. 2020.

Brasil, Ministério da Integração Nacional (2006). RELATÓRIO DO CENSO ESTRUTURAL DA PESCA DE ÁGUAS CONTINENTAIS NA REGIÃO NORTE. Belém-PA.

Brito, E. P. (2009). O papel de Palmas na rede de integração regional. Dissertação de mestrado. UFGD, Dourados, Mato Grosso do Sul, Brasil.

Brito, E. P., \& Almeida, M. G. (2017). Sentido e organização do trabalho das quebradeiras de coco no Bico do Papagaio, Tocantins. Geosul, 32(63), pp. 229-249. Acesso em: 09 jun. 2020.

Brito, E. P. (2018). SOBRE OS RIBEIRINHOS TOCANTINENSES: história e resistências. InterEspaço: Revista de Geografia e Interdisciplinaridade, 4(14), pp. 33-48. http://dx.doi.org/10.18764/2446-6549.v4n14p33-48

Brito, E. P., \& Silva, S. S. (2020). Por entre os castanhais: sujeitos e lugares no povoado fortaleza em São Geraldo do Araguaia, Pará. Caminhos de Geografia, 21(73), pp. 415-428. Disponível em: http://www.seer.ufu.br/index.php/caminhosdegeografia/article/view/49450. Acesso em: 09 jun. 2020.

Castilho, D. (2014). Modernização territorial e redes técnicas em Goiás. (Tese de doutorado). UFG, Goiânia, Brasil.

Dias, CRG e Silva, AP. (2017). Uma rede de pesca artesanal no Rio Araguaia, Tocantins, Brasil. Em Embrapa Pesca e Aquicultura - Artigo em Anais de Congresso (ALICE). In: CONGRESSO BRASILEIRO DE ENGENHARIA DE PESCA, 20., 
2017, Florianópolis. Tecnologia e inovação para pesca e aquicultura: anais. Florianópolis: FAEP-BR, 2017. Disponível em: https://ainfo.cnptia.embrapa.br/digital/bitstream/item/164542/1/CNPASA-2017conbep.pdf. Acesso em: 09 jun. 2020.

Gomes, V. F. (1862). Da cidade da Palma em Goyaz à cidade de Belém no Pará pelo rio Tocantins e breve noticia do norte da Província de Goyaz. Revista Trimestral do Instituto Histórico Geographico e Etnográfico do Brasil, 25, pp.485-513.

Lira, T. M., \& Chaves, M. D. P. S. R. (2016). Comunidades ribeirinhas na Amazônia: organização sociocultural e política. Interações (Campo Grande), 17(1). Disponível em: http://www.scielo.br/pdf/inter/v17n1/1518-7012-inter-17-01-0066.pdf . Acesso em: 25 abril. 2020.

Moss, G.\& Moss, M. (2007). Relatório Projeto Brasil das Águas. Sete Rios, São Paulo.

Silva, A. P., Ummus, M., \& Tardivo, T. (2017). Produção e sazonalidade das principais espécies capturadas pela pesca artesanal no rio Araguaia/TO. Embrapa Pesca e Aquicultura-Boletim de Pesquisa e Desenvolvimento (INFOTECA-E). Disponível em: https://ainfo.cnptia.embrapa.br/digital/bitstream/item/165181/1/CNPASA-2017bpd20.pdf. Acesso em: 09 jun. 2020.

Silva, A. P., \& de Farias, E. G. G. (2017). Caracterização participativa da frota pesqueira do Rio Araguaia-Tocantins, Brasil. Magistra, 29(1), pp. 80-90. Acesso em: 09 jun. 2020.

Tocantins (1990). Diagnóstico sócio-econômico-administrativo. Palmas, Tocantins, Brasil.

Tocantins (NATURATINS). (2019). Portaria NATURATINS no 270 DE 21/10/2019. 2019. Disponível em: https://www.legisweb.com.br/legislacao/?id=383849. Acesso em: 21 maio. 2020.

Ummus, M., Silva, A. P., \& Paz, L. D. S. (2018). Mapeamento participativo das rotas de pesca na margem tocantinense do rio Araguaia. In Embrapa Pesca e AquiculturaArtigo em anais de congresso (Alice). In: ENCONTRO NACIONAL DOS GEÓGRAFOS, 19. 2018, João Pessoa. Pensar e fazer a geografia brasileira no século XXI: escalas, conflitos socioespaciais e crise estrutural na nova geopolítica mundial: anais eletrônicos. São Paulo: AGB, 2018. Disponível em:https://ainfo.cnptia.embrapa.br/digital/bitstream/item/191520/1/CNPAF-2018eng.pdf. Acesso em: 09 jun. 2020.

Valverde, O. (1985). Estudos de Geografia Agraria brasileira. Petrópolis, Rio de Janeiro, Brasil: Vozes, p.268. 